\title{
Elementos para a discussão do conceito de gênero oral
}

Elements for discussion of oral genre concept

\author{
José Gaston Hilgert
}

Universidade Presbiteriana Mackenzie - UPM

DOI: https://doi.org/10.5902/2176148538794

\begin{abstract}
Resumo: O texto apresenta elementos para discussão do conceito de gênero oral. Retoma, com enfoque crítico, a proposta dos alemães Koch e Oesterreicher, que, para além da dicotomia fala e escrita mediais, preconizam uma oralidade e uma escrita conceptuais. Segundo ela, os gêneros distribuem-se, independentemente de sua expressão medial, num continuum que se estende dos gêneros precipuamente orais aos propriamente escritos, fazendo-se a distinção entre eles com base numa gradação de traços de oralidade e de escrita. Como contribuição crítica, propõe-se a possibilidade de definir oralidade e escrita como estratégias enunciativas projetadas nos enunciados para a produção de efeitos de sentido.
\end{abstract}

Palavras-chave: Enunciação. Gênero textual. Gênero oral. Oralidade medial. Oralidade conceptual.

Abstract: The text presents elements for discussion of the concept of oral genre. It takes a critical approach to the proposal of the Germans Koch and Oesterreicher, who, in addition to the dichotomy of medial speech (phonic) and writing (graphic), advocate a conceptional orality and writing. According to them the genres are distributed, independently of their medial expression, in a conceptional continuum that extends from the prototypically oral genres to the actual written ones. The distinction between them is based on a gradation of orality and writing traits. As a critical contribution this essay proposes the possibility of defining orality and writing as enunciative strategies revealed in texts producing different meaning effects.

Keywords: Enunciation. Textual genre. Oral genre. Medial orality. Conceptional orality. 


\section{Introdução}

A proposta do simpósio temático "Panorama atual no estudo de gêneros orais", realizado no congresso da ABRALIN, em 2019, reconhece que "o tema é amplo e implica algumas complexidades teóricas, a começar pela definição da noção de gênero oral e pela escolha de critérios teóricos que possam embasar as categorias linguísticas, interacionais e pragmáticas recorrentes no gênero analisado". Partindo dessa constatação, trouxemos para a discussão, no referido simpósio, alguns parâmetros que pudessem contribuir para uma definição José Gaston mais precisa do que seja gênero oral. o presente texto tem, portanto, Hilgert o objetivo de retomar essas ideias e ampliá-las numa exposição mais detalhada.

Inicialmente, relembramos brevemente a noção de gênero textual com base em Bakhtin (2013). A seguir, trazemos à consideração a noção de gênero oral proposta em estudos realizados e orientados por Luiz Carlos Travaglia (Travaglia et alii, 2017). Restringimo-nos a essa referência, por ser uma noção amplamente acolhida e difundida por autores brasileiros que tratam do tema. Na sequência, fazemos uma apreciação crítica dessa noção, com base no modelo de análise de gêneros textuais concebido pelos autores alemães Koch e Oesterreicher (1985, 1994, 2007, 2011 e 2016), que distinguem oralidade de escrita (Mündlichkeit / Schriftlichkeit) e, respectivamente, "língua da proximidade" de "língua da distância" (Sprache der Nähe / Sprache der Distanz). Cabe lembrar que o modelo foi difundido entre nós especialmente por Marcuschi (2001), em primeira edição, e republicado em nove outras. Incorporamos, nessa discussão, aspectos do pensamento crítico desenvolvido no decorrer dos últimos anos pela linguística alemã à obra de Koch e Oesterreicher, particularmente no que concerne à análise dos "gêneros emergentes" - como são denominados os textos produzidos e veiculados no âmbito das interações na internet (interações por e-mail, whatsapp, SMS, facebook, tweeter e outros) - com base no modelo proposto por esses autores. Fazemos, também, uma leitura e uma interpretação bakhtiniana de seus principais conceitos à luz da noção de gênero (BAKHTIN, 2013). Por fim, como contribuição crítica, propomos a possibilidade de definir oralidade e escrita como estratégias enunciativas na construção dos textos e configuração dos gêneros. 


\section{A noção de gênero}

Por mais conhecida que seja a noção de gênero discursivo desenvolvida por Bakhtin (2013), é sempre relevante explicitá-la para fundamentar um estudo que trata de gêneros textuais. Destacando, então, passagens do texto que aqui tomamos como base, o objetivo deste tópico é definir a noção de gênero, situar essa noção na base do próprio conceito de língua de Bakhtin, mostrar a sua função organizadora das práticas sociais no âmbito das atividades humanas.

Elementos

De início, chamamos atenção para uma questão terminológica. Bakhtin fala em "gênero discursivo", na medida em que as entidades que compõem um gênero são "enunciados", ou seja, instâncias discursivas, resultantes do processo da enunciação, o qual, por definição implica a interação (no mais amplo sentido desse termo) entre interlocutores, em para a discussão do conceito de gênero oral determinada situação e contexto comunicativo. O que nos autoriza usar, neste artigo, o termo "gênero textual" é a concepção que assumimos de o texto ser um enunciado, isto é, um produto da enunciação. Considerando então a afirmação de Bakhtin - "Evidentemente, cada enunciado particular é individual, mas cada campo de utilização da língua elabora seus tipos relativamente estáveis de enunciados, os quais denominamos gêneros do discurso" (p. 262) -, podemos dizer que um gênero de texto é, portanto, um conjunto de textos com estabilidade relativa no âmbito de "um campo de utilização da língua".

Os traços que convergem e entram em sintonia para definir essa relativa estabilidade dos enunciados de um gênero são de natureza composicional, temática e estilística (expressiva). A indissociabilidade desses traços fica explícita nesta passagem:

\footnotetext{
O estilo é indissociável de determinadas unidades temáticas e - o que é de especial importância - de determinadas unidades composicionais: de determinados tipos de construção do conjunto, de tipos do seu acabamento, de tipos da relação do falante com outros participantes da comunicação discursiva - com os ouvintes, os leitores, os parceiros, o discurso do outro, etc. (p. 265)
}

Em síntese, cada texto, visto em referência a seu gênero, incorpora as marcas composicionais, temáticas e estilísticas de sua enunciação, configurada por traços relativamente comuns aos demais textos desse gênero. 
José Gaston

Hilgert

Ao dizer que "cada campo de utilização da língua elabora seus tipos relativamente estáveis de enunciados", Bakhtin explicitamente vincula sua concepção de língua às práticas sociais, já que "campo de utilização de língua" remete à instância das atividades humanas que se realizam por meio de enunciados nas interações linguísticas: "Ora, a língua passa a integrar a vida através de enunciados concretos (que a realizam); é igualmente através de enunciados concretos que a vida entra na língua" (p. 265). Portanto, se os enunciados relativamente estáveis no âmbito de uma atividade humana constituem um gênero, aos gêneros cabe a própria organização da vida, o que vem ratificado em mais essa passagem: "No fundo, os estilos de linguagem ou funcionais não são outra coisa senão estilos de gênero de determinadas esferas da atividade humana e da comunicação" (p. 266).

Com esses princípios estabelecemos a orientação geral deste texto. Detalhes e interpretações específicas apresentaremos na análise crítica da proposta de Koch e Oesterreicher.

\section{Ponto de partida: a noção de gênero oral em Travaglia et alii (2017)}

Travaglia et alii (2017) reconhecem que o conceito de gênero oral não é de definição simples, particularmente quando se considera a diversidade dos objetos de análise que, em princípio, podem ser identificados como gêneros orais. 0 tema, portanto, demanda estudo e debate. Antes de apresentarem os seus critérios para essa definição, os autores, visando a dirimir ambiguidades, distinguem gênero de atividade e definem a noção de gênero.

Por atividade, seguindo o preceito bakhtiniano acima exposto, entendem o "campo de utilização da língua", no âmbito do qual realizam-se as práticas sociais dos indivíduos por meio de interações linguísticas cujos produtos são os textos. Consideram, nesse sentido, para exemplificar, o seminário, o júri, a conversação, como atividades que se realizam linguística e discursivamente por meio de diferentes gêneros. Dão evidência especial à conversação, considerando-a como atividade social realizada por conversas de diferentes gêneros, "estilística, temática e composicionalmente estáveis” (BAKHTIN, 2013, p. 264). Continuando em seu propósito de se antecipar a eventuais equívocos conceituais, tratam também de certas denominações homônimas para atividades e gêneros, como, por exemplo, a missa, o leilão, a benzeção. Nesses casos mais se questionam sobre 
a possibilidade de um mesmo termo denominar um gênero ou uma atividade do que fazem afirmações categóricas. Importa-lhes mesmo chamar atenção para o problema e demandar decisões teóricas a fim de que essas questões possam tornar-se objeto de pesquisa.

Na sequência definem, então, gênero, adotando, explicitamente, a perspectiva baktiniana:

Elementos

um tipo de enunciado relativamente estável, ou seja, com determinadas regularidades em termos de conteúdo temático, construção composicional, forma de realização linguística (estilo), criado em uma esfera de atividade humana ou por uma comunidade discursiva, no dizer de Swales (1990), para realizar uma ação social por meio da linguagem (TRAVAGLIA et al., 2017, p. 15). para a discussão do conceito de gênero oral

E acrescentam a esse conceito o princípio de que o gênero é "um pré-acordo de um grupo social sobre o modo de realizar algo linguística e discursivamente por meio de textos" (p.15).

Definida a noção de gênero, voltam novamente à distinção entre atividade e gênero, reiterando que atividades são ações humanas, social e historicamente organizadas, que buscam objetivos determinados. Gêneros são "instrumentos linguístico- discursivos" por meio dos quais se realizam essas atividades, sendo que os objetivos e as funções sociais destas determinam a caracterização dos gêneros.

Finalmente, os autores definem o que é gênero oral, estabelecendo dois critérios fundamentais para reconhecê-lo: ter como suporte a voz humana e ser produzido para ser realizado oralmente. E acrescentam: textos produzidos por escrito para serem oralizados são gêneros orais; há gêneros que são orais em sua origem, mas possuem paralelamente um registro escrito; há gêneros que são orais sempre (produzidos e realizados oralmente). Em síntese, é o caráter oral (tendo como meio de expressão a voz humana) da atividade linguístico-discursiva que define o gênero oral. Nessa perspectiva, consideram gêneros orais uma conferência e uma comunicação científica, pois foram elaboradas para serem apresentadas oralmente, ainda que tenham uma versão escrita. O mesmo valeria para uma peça de teatro, cujo texto foi escrito, mas destinado à representação oral. Alertam, no entanto, que não é uma simples oralização (uma leitura, por exemplo) de um texto produzido 
José Gaston

Hilgert para ter divulgação escrita que lhe conferirá caráter de oralidade. Para tanto importa que o texto seja concebido, na comunidade discursiva em que é produzido e veiculado, como de realização oral, isto é, tendo a voz humana como suporte de realização.

Fica claro, em sua proposição, que os autores buscam uma definição de gênero oral a mais objetiva possível, visando, em última instância, à configuração precisa do objeto de pesquisa gênero oral. Essa é, com certeza uma contribuição de imenso mérito que os autores ofereceram à comunidade científica que estuda os gêneros textuais para fins teóricos ou para subsidiar e orientar o trabalho com textos no ensino da língua portuguesa e mesmo no de línguas estrangeiras.

No entanto - os próprios autores admitem isso -, não há unanimidade em relação à definição proposta. Há gêneros que, segundo os critérios propostos, são orais, mas que, sob outro ponto de vista, são fortemente marcados por traços que os usuários da língua, digamos, consensualmente reconhecem como próprios de gêneros escritos. Da mesma forma, há textos que, de acordo com critérios referidos, são escritos, mas os usuários da língua os percebem, em grau maior ou menor, tanto na produção quanto na recepção, como caracterizados pela oralidade. É o caso, por exemplo, dos chamados gêneros emergentes. Um whatsapp, por exemplo, é um texto produzido por escrito e destinado à divulgação escrita. Pela proposta apresentada, ele deve ser considerado um texto escrito. Acreditamos, no entanto, que haja unanimidade entre os usuários da língua que esse gênero é - para não dizer oral, já que se apresenta na forma escrita - em todas as suas características marcado pela oralidade.

Em termos gerais, pode-se dizer, então, que os critérios da proposta analisada são, ao mesmo tempo, amplos demais e restritos demais: amplos, porque consideram gêneros orais textos que são, sim, orais em sua realização final, mas vêm fortemente marcados pela escrita em sua percepção e produção; e restritos, por não darem conta da tensão entre fala e escrita existente em muitos gêneros, particularmente nos emergentes já referidos. Partindo, então, dessas considerações, retomamos, na sequência, a proposta de Koch e Oesterreicher num enfoque crítico, para trazer ao debate outros critérios de definição de gênero oral. 


\section{A proposta de Koch e Oesterreicher: um enfoque crítico}

A primeira versão da proposta de Peter Koch e Wulf Oesterreicher foi publicada em 1985, e teve grande receptividade, particularmente em países de língua alemã. No percurso de seus mais de 30 anos de existência sofreu, como acontece com toda proposta teórica, reformulações, desenvolvimentos e críticas. Na verdade, os autores em quase nada alteraram sua proposta. As contribuições e sugestões críticas para sua aplicação em análise de textos de diferentes gêneros vieram dos linguistas, especialmente os dos campos da Linguística Textual e da Análise da Conversação. Uma série de ensaios críticos foram publicados recentemente em obra organizada por Feilke e Hennig (2016), intitulada Sobre a carreira de "proximidade e distância": recepção e discus-

Elementos para a discussão do conceito de gênero oral são do modelo de Koch e Oesterreicher. O primeiro ensaio é dos próprios fundadores da proposta, com o título: 30 anos de "língua da proximidade - língua da distância": sobre o início e o desenvolvimento dos conceitos no âmbito da oralidade e da escrita. ${ }^{1}$ Focaliza-se com destaque, nos ensaios, a tensão entre oralidade e escrita dos novos gêneros, concebidos e percebidos pelos usuários como fortemente marcados pela oralidade, em alguns casos de forma exacerbada, em decorrência, a nosso ver, de um traço marcante das interações nas redes sociais, que é a busca da visibilidade (BASTOS, 2018). Na produção de muitos desses gêneros, entram recursos constitutivos dos textos que que visam a esse fim, a ponto de alguns terem ou ao menos sugerirem a configuração de interações face a face.

Koch e Oesterreicher reconhecem a demasiada simplificação de uma proposta dicotômica que distinguisse textos orais de escritos unicamente por sua forma de manifestação, ou seja, pela fala (fônicos) e pela escrita (gráficos). Incorporando essa distinção em nova proposta, desenvolveram a distinção entre oralidade medial e conceptual e entre escrita medial e conceptual. Por medial, continuam os autores considerando as representações gráfica e fônica dos textos. A inovação está no caráter conceptual da oralidade e da escrita. Resumidamente, pode-se dizer que, por conceptual, entendem a concepção (no sentido de percepção) que os usuários da língua têm, no âmbito de suas práticas sociais,

1 Ambos os autores já são falecidos (Koch, em 2014 e Oessterreicher, em 2015). 0 esboço do artigo havia sido feito por Peter Koch para uma conferência. Wulf Oesterreicher o desenvolveu na forma desse artigo mas faleceu antes da publicação da obra que o divulgou. 
José Gaston Hilgert

de um gênero ser, com base em suas características de produção e de construção, de caráter oral ou escrito, independentemente de sua expressão medial. Quanto mais o texto, por suas características, evoca a fala - a linguagem das relações de proximidade -, mais ele é percebido como conceptualmente falado. Quanto mais seus traços lembram a escrita - a linguagem das interações do distanciamento -, mais ele é reconhecido como conceptualmente escrito.

Embora Koch e Oesterreicher não façam referência a Bakhtin em seus textos, pode-se fazer uma interpretação bakhtiniana da noção de conceptualidade, com base nesta passagem de Bakhtin (2013, p. 266):

Uma determinada função (científica, técnica, publicística, oficial, cotidiana) e determinadas condições de comunicação discursiva, específicas de cada campo, geram determinados gêneros, isto é, determinados tipos de enunciados estilísticos, temáticos e composicionais relativamente estáveis.

Um gênero será, então, conceptualmente oral ou escrito se ele tiver configuração estilística, temática e composicional oral ou escrita, independentemente de sua expressão medial, configuração essa determinada pela função e as condições de comunicação discursivas do campo de ação humana em que o gênero veicula.

A percepção da oralidade e da escrita, nessa perspectiva conceptual, nós a internalizamos com o aprendizado da língua, até porque aprendemos a língua nas enunciações, isto é, no uso dos gêneros nos variados contextos das atividades humanas.

A língua materna - sua composição vocabular e sua estrutura gramatical - não chega ao nosso conhecimento a partir de dicionários e gramáticas, mas de enunciações concretas que nós mesmos ouvimos e nós mesmos reproduzimos na comunicação discursiva viva com as pessoas que nos rodeiam. Nós assimilamos as formas da língua somente nas formas das enunciações e justamente com essas formas. As formas da língua e as formas típicas dos enunciados, isto é, os gêneros do discurso, chegam à nossa experiência e à nossa consciência em conjunto e estreitamente vinculadas. (pp. 282-283) 
Nós aprendemos a moldar o nosso discurso em formas de gênero e, quando ouvimos o discurso alheio, já adivinhamos o seu gênero pelas primeiras palavras, adivinhamos um determinado volume (isto é, uma extensão aproximada do conjunto do discurso), uma determinada construção composicional, prevemos o fim, isto é, desde o início temos a sensação do conjunto do discurso que em seguida apenas se diferencia no processo da fala (p. 283).

Elementos

para a

discussão do

Aprendemos, então, a falar a língua, dominando-a em seu léxico, em sua estruturação gramatical, em suas formas expressivas, na medida em que a usamos nos variados gêneros que organizam as nossas interações nas diferentes atividades que realizamos no percurso de nossa conceito de gênero oral existência. Ao mesmo tempo, portanto, em que o domínio da língua se desenvolve, vamos internalizando a percepção da adequação da estrutura composicional, das escolhas temáticas, das peculiaridades expressivas, às diferentes situações em que nossa atuação discursiva é exigida. Isso implica dizer que aprendemos em nossa trajetória linguística a perceber se a situação de uso da língua demanda, seja de nossa parte, seja de nosso interlocutor, um gênero marcado pela oralidade ou com traços dos gêneros escritos.

Essa percepção, voltando agora a Koch e Oesterreicher, não depende de o texto ser escrito (gráfico) ou oral (fônico) em sua expressão medial. Deve-se admitir, contudo, que a expressão fônica de um gênero é um fator favorável à configuração da oralidade conceptual, e a expressão gráfica de um gênero é uma condição que predispõe à escrita conceptual (DÜRRSCHEID, 2016; KOCH e OESTERREICHER, 2016).

Os autores definem dois polos de um continuum em que se distribuem os gêneros textuais, que vão do polo da oralidade conceptual prototípica (uma conversa, por exemplo) ao polo da escrita conceptual (o texto de uma lei, por exemplo). Definem a oralidade como sendo a linguagem da proximidade; a escrita, como a linguagem do distanciamento. Transcrevemos aqui a visualização gráfica de seu modelo, conforme vem registrado em Koch e Oesterreicher (1994). 


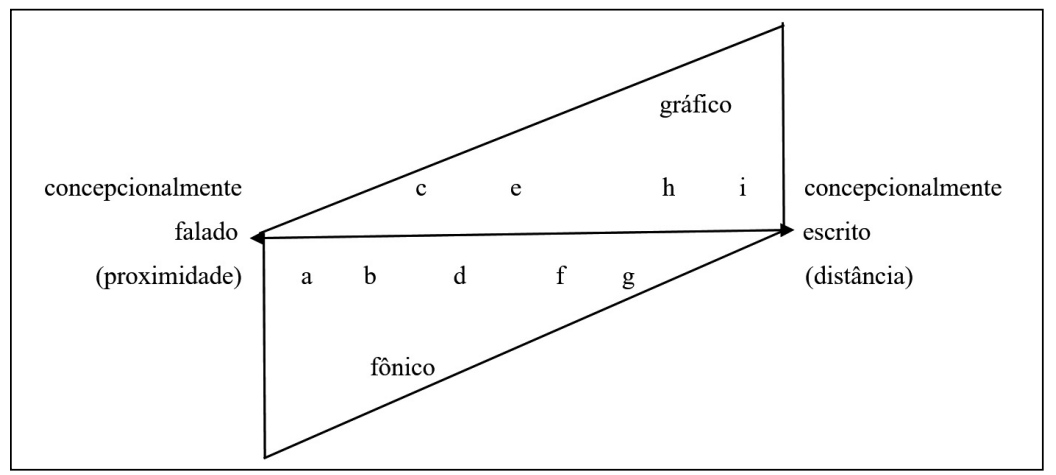

José Gaston

Hilgert

Figura 1 - Continuum proximidade/distância (Koch/Oesterreicher 1994, p. 588): a = conversa familiar, $b=$ conversa telefônica, $c=$ carta privada, $d=$ entrevista de trabalho, $e=$ entrevista de jornal, $\mathrm{f}=$ sermão, $\mathrm{g}=$ palestra científica, $\mathrm{h}=$ editorial, $\mathrm{i}=$ texto legal.

Em seu último texto, de 2016, retomam o mesmo gráfico com algumas especificações: em (a), onde diziam "conversa familiar", falam em "conversa espontânea entre amigos"; em (b), "conversa telefônica" substituíram por "conversa telefônica familiar"; em (c), "carta privada" por "carta privada entre amigos"; os gêneros identificados por (d), (e), (f), (g), (h) e (i) são os mesmo referidos no gráfico de 1994.

Embora aparentemente possam parecer alterações de menor importância, elas refletem o eco da crítica feita ao modelo (DÜRRSCHEID, 2016; ANDROUTSOPOULOS, 2007, KNOPP, 2013; FEHRMANN e LINZ, 2009; AGEL e HENNIG, 2006). A denominação "conversa familiar" pode abarcar gêneros vários, de diferentes graus de oralidade e de proximidade, daí a especificação para "conversa espontânea entre amigos", que aponta - valendo-nos da formulação bakhtiniana -, para um gênero cujos textos revelam uma "estabilidade relativa" maior; a mesma razão de especificação vai-se registrar na passagem de "carta privada" para "carta privada entre amigos".

Juntamente com o gráfico, os autores relacionam características que identificam um gênero como conceptualmente oral ou conceptualmente escrito e que o posicionam, no continuum, mais próximo do polo da oralidade/da linguagem da proximidade ou do polo da escrita/da linguagem do distanciamento. Numa interpretação bakhtiniana, poder-se-ia dizer que o conjunto de características concorre para a configuração estilística (expressiva), temática e composicional dos gêneros. Koch e Oesterreicher propõem duas categorias distintivas: a) as condições de comunicação; e b) as estratégias de verbalização. Cabe registrar que 
os traços que eles apontam no texto de 2016 - os que a seguir relacionamos - são praticamente os mesmos que eles já relacionavam no de 1985, conforme eles mesmos afirmam: "Os resultados a que chegamos em nossos estudos podem ser reunidos no seguinte esquema que, com pequenas adaptações terminológicas, nós usamos desde 1985" (2016, p. 26). Destaque-se que as listagens de características terminam com o "etc.", mostrando que elas podem ou devem ser ampliadas.

Elementos

para a

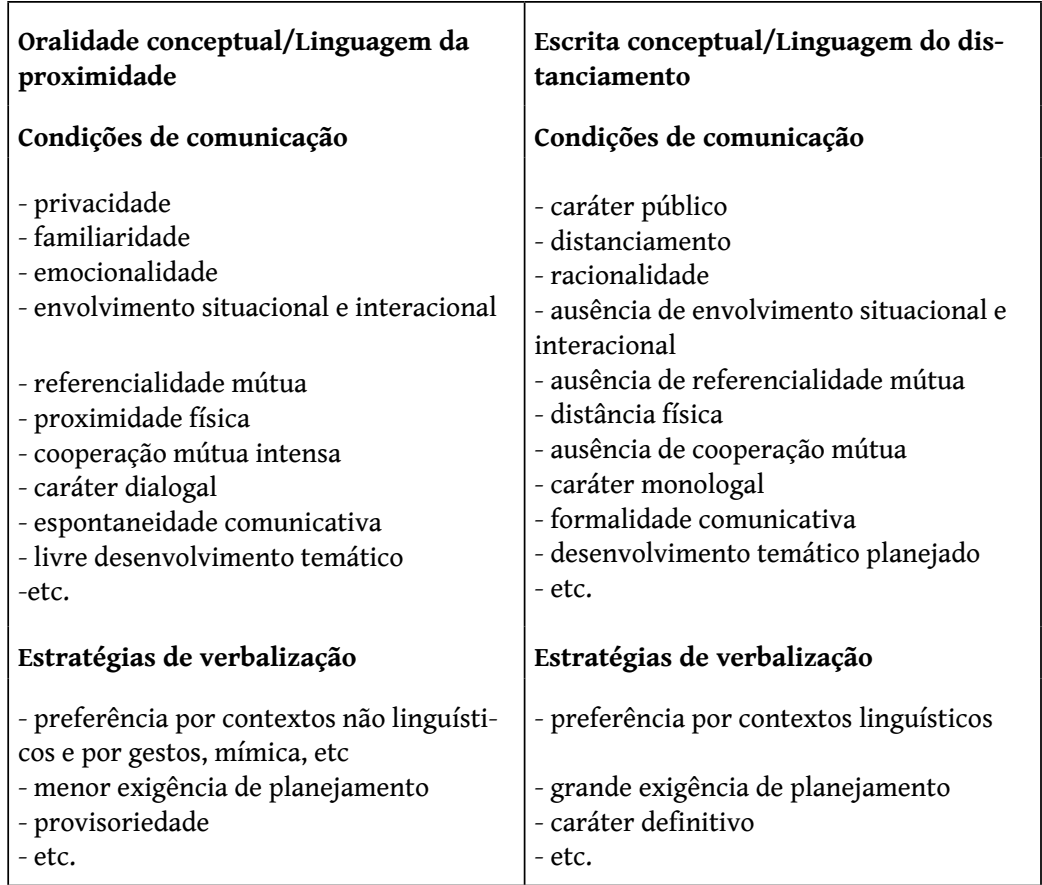

discussão do conceito de gênero oral

Figura 2 - Koch e Oesterreicher (2016, p. 26)

Em relação a essas dimensões, particularmente em relação às primeiras, os autores fazem uma série de observações (KOCH e OESTERREICHER 2016, p. 24 e 25): na caracterização dos gêneros, todas elas precisam ser compreendidas como sendo de natureza continuada, ou seja, assumindo um caráter de gradação (mais ou menos); não podem ser vistas isoladamente, mas sempre em combinação com outras dimensões; cada evento linguístico-comunicativo, isto é, cada gênero se configura a partir de uma "síntese de diferentes parâmetros", não fazendo, portanto, sentido tomar um único deles para classificar um gênero como marcado pela oralidade ou pela escrita conceptuais; as dimensões precisam ser entendidas como historicamente definidas, já que elas, como, por 
exemplo, "privacidade", “caráter público", "familiaridade”, “distanciamento", podem ser avaliadas de forma diferente em épocas distintas. $\mathrm{E}$ concluem, afirmando:

Em síntese, é fundamental que se considere que as dimensões apresentadas ainda não são fatos linguísticos, mas unicamente fatores que determinam e orientam, como condições de enquadramento, a verbalização fônica e gráfica no continuum conceptual. Também as estratégias de verbalização são essencialmente definidas como de natureza conceptual (p. 25).

Hilgert

Uma das críticas feitas ao modelo de Koch e Oesterreicher é a de que eles se limitam à expressão linguística, quando definem o que é "meio", dificultando, dessa forma o uso do modelo para análise dos gêneros emergentes. A esse propósito se manifesta Dürrscheid (2016, p. 360): “Por 'meio' entendem Koch/Oesterreicher a forma de realização de um enunciado, mais precisamente: a dicotomia fônico-gráfica - nem mais nem menos”. Em resposta à crítica, duas observações dos autores:

Aqui é também o lugar para a abertura ao enfoque dos contextos comunicativos paralinguísticos, especialmente das modalidades comunicativas semióticas não linguísticas, que são importantes no âmbito dos "novos meios" e em seus formatos multimodais (2016, pp. 25 e 26).

Além do mais, é precisamente o chat um dos exemplos mais bonitos de uma aproximação, realizada por um meio gráfico, à linguagem dialogal e espontânea da proximidade. Também as tão apreciadas abreviações e emoticons se explicam conceptualmente na perspectiva da rapidez na escrita, estimuladora da espontaneidade (2016, p. 53-54).

Em síntese, rebatem a crítica, afirmando que os novos gêneros podem perfeitamente ser integrados no continuum, situando-se, tendencialmente próximos do polo da oralidade conceptual, ou seja, como linguagem da proximidade. No entanto, não se aprofundam teórica nem analiticamente nesse campo específico do estudo dos gêneros. 
Uma outra crítica à proposta de Koch e Oesterreicher é a de que o caráter oral, a linguagem da proximidade, portanto, somente decorreria do contexto de produção e uso do gênero. Segundo Androutsopoulos (2007, p. 80), essa é uma visão parcial da relação entre texto e contexto. Não é somente o contexto dado que determina o caráter de oralidade ou de escrita de um texto ou de um gênero, mas os recursos linguístico-discursivos usados em sua construção são igualmente determinantes desse caráter.

Elementos para a

o fato de a situação determinar a escolha dos meios linguísticos discussão do não pode ser mantido à luz da relação texto-contexto desenvolviconceito de da na mais recente estilística e sociolinguística interacional (cf., por exemplo, Selting 1997). A língua, nesse sentido, é também constitutiva do contexto e pode mudá-lo. Assim, por exemplo, gênero oral situações de distanciamento podem ser simbolicamente redefinidas por meio de estratégias de construção linguística, conforme já foi sobejamente mostrado na análise linguística dos meios de comunicação social (cf., por exemplo, Holly 1996; Burger 2005). A linguagem da proximidade na internet, portanto, não pode ser unicamente compreendida como o uso linguístico que só reflete uma situação de proximidade de uma situação de fala dada, mas, também, de uma proximidade ativamente criada."

Essa crítica de Androutsopoulos encerra, a nosso ver, uma outra à proposta dos autores alemães, a de vincularem sua noção de oralidade e escrita conceptuais e, portanto, de linguagem da proximidade e de distanciamento preponderantemente a uma proximidade e a um distanciamento físicos, afetivos ou de hierarquia social. Não consideram, portanto, a criatividade enunciativa de produção de efeitos de oralidade e de proximidade, de escrita e de distanciamento. Com essa observação vamos ao último tópico deste texto.

\section{A oralidade e escrita como efeitos de oralidade e de escrita}

Já dissemos acima que oralidade é o caráter de qualquer texto, medialmente falado ou escrito, que, na percepção do usuário da língua, evoque traços da fala, mais ou menos recorrentes em interações face a face e, por isso, produtores de efeitos de sentido de proximidade. Já escrita é o modo de ser dos textos, não importa se medialmente falados ou escritos, percebidos 
José Gaston

Hilgert

pelo usuário da língua como próprios das interações por escrito e, por isso, produtores de efeitos de sentido de distanciamento. Dissemos também que, como usuários da língua no uso dos gêneros, internalizamos com o aprendizado dela a percepção de adequação dos gêneros, com suas propriedades composicionais, temáticas e estilísticas, às variadas situações e práticas sociais. Para uma conversa entre amigos sabemos ou, mais especificamente, percebemos que devemos tratar o interlocutor por "você" pois, assim, se criará uma simetria interacional, e não por "senhor", que resultaria num efeito de distanciamento e de assimetria interlocutiva. A interação eu-você instaura uma "cenografia", isto é, uma "cena de fala" (MAINGUENEAU, 2006) que vai demandar que os demais recursos linguístico-discursivos que caracterizarão o gênero em realização - léxico, sintaxe, figuras, estilo, escolhas temáticas - sintonizem com ela. O mesmo ocorre, por exemplo, com um e-mail entre aluno e professor, para citar um gênero por meio do qual muito interagimos em nosso cotidiano profissional: ${ }^{2}$.

\footnotetext{
Professor,

Boa tarde!

Estou no penúltimo semestre do curso de Letras e já conversei com alguns professores sobre o tema do meu TGI. Qaundo conversei com o Prof. Arthur, ele me aconselhou a conversar com voce já que quero abordar as diferenças de texto. Vou escrever sobre a adaptação do conto de Machado de Assis «O alienista» em quadrinhos e quero falar mais sobre intertextualidade do que literatura já que meu público alvo são alunos de ensino fundamental. Tentei falar com você hoje depois da aula, mas não consegui. Tem algum outro horário que você está na Universidade pela manhã? Aguardo sua resposta, Desde já, obrigada! Vera
}

Há evidentemente, por parte do aluno, uma clara percepção, internalizada por ele no próprio uso do gênero, de que esse é o "cenário de fala" adequado para interagir com o professor - que ele conhece ou do qual seja provavelmente aluno - para tratar de assuntos acadêmicos. As características lexicais, sintáticas, estilísticas e temáticas concordam

2 Exemplo extraído de corpus do autor. Os nomes mencionados no e-mail são fictícios. 
com o cenário e, claramente, configuram um gênero que se situa próximo do polo da oralidade, mas não tanto quanto uma conversa entre amigos. Esse certo afastamento do polo deve-se, ao menos, a duas razões: a) o fato de ser uma interação entre professor e aluno no âmbito acadêmico, entre os quais existe uma relação profissional e não propriamente de amizade, havendo, portanto, um certo distanciamento nessa relação; b) o fato de o texto ser medialmente escrito, fator que, no próprio dizer do Koch e Oesterreicher (2016, p. 53-54), “exerce um efeito de 'contenção' em relação à linguagem da proximidade, que não pode ser subestimado".

Observe-se que, no e-mail, o aluno interpela o mestre pelo título profissional e institucional que lhe é próprio: "Professor". A escolha produz um evidente efeito de certo distanciamento. Efeito

Elementos para a discussão do conceito de gênero oral em direção contrária produz o recurso do "leitor invocado" (MAINGUENEAU, 2008, p. 34), que é a interpelação do destinatário por seu nome ou até por apelido ou nome de trato familiar, como se pode observar nesta carta de Graciliano Ramos a sua amada, escrita em $1^{\circ}$. de setembro de 1932:

Ló: Todos nós vamos indo, com muitas saudades de você. Não lhe tenho escrito ultimamente porque não tenho nada para contar. Neste ramerrão de todos os dias parece que vou ficando estúpido. A última carta sua que recebi dizia que tudo por aí estava a contento e falava-me em sessenta mil-réis que v. ia pedir ao Antônio. Creio que v. ainda não tinha recebido uma que lhe mandei há alguns dias, com dinheiro. Se necessitar alguma coisa, avise-me para eu tomar aqui as providências. Continuo a consertar as cercas do S. Bernardo. Creio que está ficando uma propriedade muito bonita. E se Deus não mandar o contrário, qualquer dia terei de apresentá-la ao respeitável público. o último capítulo, com algumas emendas que fiz, parece que está bom. Não temos aqui nenhuma notícia certa da revolução. 0 rádio desapareceu, os jornais não dizem nada, até os boatos são escassos. De sorte que estamos como presos, ignorando tudo o que se passa além dos montes que nos cercam. Adeus, por hoje, Ló. Lembranças a seu Américo e às meninas. Um abraço para você. Beije por mim Lulu e Tatá. Gato. 1ํ de setembro de 1932. (P. dos Índios). 
José Gaston Hilgert

A carta é um belo exemplo do gênero epistolar entre pessoas íntimas, caráter já identificado ao começar com "Ló" em vez de Heloísa. A interpelação nominal explícita do destinatário em duas ocasiões cria um efeito de conversa. Os demais recursos lexicais, a recorrência dos verbos no presente do indicativo - que produz um efeito de enunciação aqui e agora -, a sintaxe em períodos simples, os temas do cotidiano são todas estratégias que evocam, ainda que de forma "contida" a interação face a face, ou seja, a oralidade conceptual e seus efeitos de proximidade.

Voltando ao início desse tópico, queremos, com essa breve exemplificação, corroborar as considerações de Androutsopoulos (2007) e até avançar em relação a sua crítica, dizendo que, por mais que as condições reais de proximidade ou de distanciamento levem a produção de um texto com as características demandadas pela situação de interação, os fatores linguístico-discursivos configuradores do gênero sempre serão, em última instância, escolhas dos interlocutores. Tanto a conversa, quanto o e-mail e a carta poderiam, por exemplo, sofrer reformulações composicionais e estilísticas com vistas à produção de determinados efeitos de sentido. Bakhtin (2013, p. 284) aponta para essa perspectiva quando fala dos "matizes de uma entonação expressiva (pode-se assumir um tom mais seco ou mais respeitoso, mais frio ou mais caloroso, introduzir a entonação de alegria, etc.)". Embora se refira, no contexto, aos gêneros particularmente "elevados, oficiais [que] possuem um alto grau de estabilidade e coação", pode-se estender o princípio a qualquer gênero e a qualquer instância de sua produção - seja em expressão media oral ou escrita - e também a qualquer um dos componentes configuradores de um gênero, o composicional, o temático e o estilístico.

Em sintonia com a modulação expressiva, Bakhtin fala também da "reacentuação dos gêneros", a qual diz ser "uma caracterização da comunicação discursiva em geral". Com "reacentuação dos gêneros" o autor denomina as possibilidades de transferir elementos de um gênero a outro, misturando-os assim, levando à criação de novos sentidos.

Resumindo, é certo que o campo de atuação humana, isto é, a situação de uso da língua determina a escolha do gênero por meio do qual se realiza a interação nessa situação. No entanto, essa situação nada mais é do que a instância da vida realizada pela enunciação e, ao mesmo tempo determinante desta, conforme vimos em Bakhtin. Por força dessa determinação, o enunciador faz a escolha dos traços composicionais, temáticos e expressivos que vão configurar o gênero próprio para a realização 
da atividade em curso, e que podem, em razão da construção de novos sentidos, receber "matizes" e "reacentuações", por vezes criativas e inesperadas. Nessa perspectiva, pode-se dizer que os traços de oralidade no enunciado, isto é, no texto, são marcas da enunciação nele projetadas que produzem efeitos de sentido de oralidade. Pensamos que as características de oralidade relacionadas por Koch e Oesterreicher e outras mais podem ser compreendidas nesse sentido. Quanto maior for a convergência desses traços no texto, mais intenso será o sentido de oralidade e de proximidade por eles produzidos. É a gradação e a natureza desses traços que permite observar efeitos de uma proximidade contida no e-mail apresentado. Já na carta de Graciliano ela se revela mais intensa a ponto de se poder falar em efeitos de intimidade ou de cumplicidade.

Elementos para a discussão do conceito de gênero oral

\section{Considerações finais}

Foi propósito deste texto oferecer elementos para a discussão do conceito de gênero oral, noção fundamental para configurar com precisão um dos objetos de estudo mais em evidência na Linguística Textual e na Análise da Conversação. Parte-se da noção de gênero proposta por Bakhtin (2013) e da noção de gênero oral definida por Travaglia et alii (2017). Em relação a essa última noção, ponderou-se que ela, por seus critérios, considera, por um lado, orais gêneros que, embora realizados oralmente, têm evidentes marcas de escrita e circulam em âmbitos discursivos nos quais os gêneros escritos têm predomínio; (b) por outro lado, os mesmos critérios não dão conta de gêneros explicitamente marcados pela oralidade e usados em situações que demandam gêneros orais, mas que realizam a interação por escrito. Diante dessa questão, retomamos, com enfoque crítico, a proposta de Koch e Oesterreicher, divulgada em sua primeira versão em 1985 e, com últimos adendos, em 2016. Os autores alemães classificam os gêneros textuais em duas perspectivas: a primeira, focalizando sua manifestação medial, distingue textos orais de textos escritos, com base em seu caráter respectivamente fônico e gráfico; a segunda, levando em conta seu caráter conceptual, ou seja, a percepção do caráter oral e escrito, independentemente de sua expressão medial, que o usuário da língua tem na caracterização dos gêneros no contexto de seu uso nas práticas sociais.

Fizemos uma análise dessa proposta à luz das críticas que recebeu em seus já 30 anos de percurso. Entre estas, destaca-se a de Androutpoulos (2007) que considera estar a noção de oralidade conceptual de- 
masiadamente vinculada à determinação do contexto de proximidade física, afetiva ou social dos interlocutores, esquecendo-se de que essa proximidade pode ser ativamente criada pelo enunciador por meio do acionamento de determinadas estratégias linguístico-discursivas na construção do texto.

Acrescentamos a esse posicionamento crítico a ideia de que as condições de uso de um determinado gênero constituem a instância determinadora da enunciação ou, mais especificamente, definem a escolha das propriedades composicionais, temáticas e expressivas configurado-

José Gaston Hilgert ras do gênero. Isso significa dizer que a oralidade conceptual é criada na enunciação do enunciado-texto e nele está disseminada por uma convergência de diferentes traços de oralidade. $O$ estudioso da Linguística Textual ou da Análise da Conversação tem como objeto de estudo os enunciados, os textos e, para tanto, não precisa, em princípio, conhecer as reais condições de sua produção, saber da proximidade física, afetiva ou social dos interlocutores. O que importa é o produto da enunciação posto à consideração do analista, isto é, o texto, medialmente falado ou escrito. Nele estão inscritas as marcas da oralidade que cabem ser percebidas e identificadas pelo analista, orientado por seus fundamentos teóricos e metodológicos. Concluindo, voltamos ao continuum de Koch e Oesterreicher. Nele os gêneros orais estarão mais ou menos próximos do polo da oralidade, na medida em que apresentem, em maior ou menor grau, traços que produzam efeitos de oralidade e de proximidade.

\section{REFERÊNCIAS}

AGEL, Vilmos; HENNIG, Mathilde. Überlegungen zur Theorie und Praxis des Nähe- und Distanzsprechens. In: (org). Grammatik aus Nähe und Distanz: Theorie und Praxis am Beispiel von Nähetexten. Tübingen: Niemeyer. 2006, pp. 1650-2000.

ANDROUTSOPOULOS, Jannis K. "Neue Medien - neue Schriftlichkeit?". Mitteilungen des Deutschen Germanistenverbandes, 2007, n. 1, pp. 72-97.

BAKHTIN, Mikahil. Os gêneros do discurso. In: Estética da criação verbal. São Paulo: Martins Fontes, 2003, pp. 261-306. 
BASTOS NETO, Adalberto. 0 modo de presença da rede social: interação e visibilidade no Facebook. Tese de doutorado. 2018.

DÜRSCHEID, Christa. E-Mail: eine neue Kommunikationsform? In: MORALDO, Sandro M. (org.). Internet.kom Sprach-und kommunikationsformen im WorldWideWeb. Edição italiana e alemã. Vol. 2 Medialität, Hypertext, digitale Literatur. Rom: Aracne, 2011, pp. 39-70.

Elementos para a discussão do conceito de gênero oral

FEHRMANN, Gisela; LINZ, Erika. Eine Medientheorie ohne Medien? Zur Unterscheidung von konzeptioneller und medialer Mündlichkeit und Schriftlichkeit. In: BIRK, Elisabeth / SCHNEIDER, Jan G. (org.) Philosophie der Schrift. Tübigen: Max Niemeyer, 2009, p. 123-143.

KNOPP, Matthias. Mediale Räume zwischen Mündlichkeit und Schriftlichkeit: Zur Theorie und Empirie sprachlicher Handlungsformen. (Tese), 2013. Disponível em http://kups.ub.uni-koeln.de (Acesso em 16.6.2019).

KOCH, Peter; OESTERREICHER, Wulf. 30 Jahre "Sprache der Nälhe Sprache der Distanz". Zu Anfängen und Entwicklung von Konzepten im Feld von Mündllichkeit und Schriftlichkeit. In: FEILKE, Helmuth e HENNIG, Mathilde (org). Zur Karriere von "Nähe und Distanz": Rezeption und Diskussion des Koch-Oesterreicher-Modells, 2016, p. 11-72.

Gesprochene Sprache in der Romania: Französisch, Italienisch, Spanisch. 2. ed. atualizada e ampliada. Berlin/New York: de Gruyter, 2011 (1990)

Schriftlichkeit und kommunikative Distanz. Zeitschrift für germanistische Linguistik, 2007, 35, pp. 346-375. 
Schriftlichkeit und Sprache. In: GÜNTHER, Hartmut/ LUDWIG, Otto (org.): Schrift und Schriftlichkeit: ein interdisziplinäres Handbuch internationaler Forschung. An Interdisciplinary Handbook of International Research. Vol. 1. Berlin/New York: de Gruyter, 1994, pp. 587-604.

Sprache der Nähe - Sprache der Distanz. Mündlichkeit und Schriftlichkeit im Spannungsfeld von Sprachtheorie und Sprachgeschichte. Romanistisches Jahrbuch, 1985, 36, pp. 15-43.

José Gaston

Hilgert MARCUSCHI, Luiz Antônio. Da fala para a escrita: atividades de retextualização.1. ed. São Paulo: Cortez, 2001.

RAMOS, Graciliano. Cartas. 8. Ed. Rio de Janeiro: Record, 2011.

TRAVAGLIA, Luiz Carlos et alii. Gêneros orais: conceituação e caracterização. Olhares \& trilhas. Gêneros orais: caracterização e ensino. Organização de Travaglia, L. C. Vol. 19, no. 2, jul/dez 2017, p. 12-24.

ZEMAN, Sonja. "Mündlichkeit" ist nicht gleich "Mündlichkeit": Implikationen für eine Theorie der Gesprochenen Sprache. In: HAGEMANN, Jörg; KLEIN, Wolf P. e STAFFELDT, Sven (org.). Pragmatischer Standard. Tübigen: Stauffenburg Verlag 2013, pp. 191-205. 